\title{
ANALYSIS ON THE EFFECT OF SPATIAL AND SPECTRAL RESOLUTION OF DIFFERENT REMOTE SENSING DATA IN SUGARCANE CROP YIELD STUDY
}

\author{
Sh. Akbarian ${ }^{1}$, C.-Y. Xu ${ }^{2}$, S. Lim ${ }^{1, *}$ \\ ${ }^{1}$ School of Civil and Environmental Engineering, University of New South Wales, Sydney, Australia - (s.akbarian, \\ s.lim)@unsw.edu.au \\ ${ }^{2}$ School of Health, Medical and Applied Sciences, Central Queensland University, Bundaberg, Australia - c.xu@cqu.edu.au
}

KEY WORDS: Normalized Difference Vegetation Index (NDVI), Normalized Difference Red Edge Index (NDRE), Vegetation Indices (VIs), WorldView-2 (WV2), Unmanned Aerial Vehicle (UAV), Leaf Area Index (LAI)

\begin{abstract}
:
Sugarcane is a perennial crop that contributes to nearly $80 \%$ of the global sugar-based products. Therefore, sugarcane growers and food companies are seeking ways to address the concerns related to sugarcane crop yield and health. In this study, a spatial and spectral analysis on the peak growth stage of the sugarcane fields in Bundaberg, Queensland, Australia is performed using the Normalized Difference Vegetation Index (NDVI) and Normalized Difference Red Edge Index (NDRE) derived from highresolution WorldView-2 (WV2) images and multispectral Unmanned Aerial Vehicle (UAV) images. Two topics are chosen for this study: 1) the difference and correlation between NDVI and NDRE that are commonly used to estimate Leaf Area Index, a common crop parameter for the assessment of crop yield and health stages; 2) the impact of spatial resolution on the systematic difference in the abovementioned two Vegetation Indices (VIs). The statistical correlation analysis between the WV2 and UAV images produced correlation coefficients of 0.68 and 0.71 for NDVI and NDRE, respectively. In addition, an overall comparison of the WV2 and UAV-derived VIs indicated that the UAV images produced a better accuracy than the WV2 images because UAV can effectively distinguish various status of vegetation owing to its high spatial resolution. The results illustrated a strong positive correlation between NDVI and NDRE, each derived from the WV2 and UAV images, and the correlation coefficients were 0.81 and 0.90 , respectively, i.e. the correlation between NDVI and NDRE is higher in the UAV images than the WV2 images.
\end{abstract}

\section{INTRODUCTION}

With the increase of the world population, the amount of food and farming sources needs to be upgraded too. Precision agriculture (PA) is one of the most effective methods that have been implied to decrease cost, resolve environmental complication and enhance quality and quantity of the agricultural products (Lambert and Lowenberg-DeBoer, 2000). Decisions on the farming operations and the maximization of the efficiency of outputs in PA need high spatial and temporal resolution data of crop status (Huang et al., 2013). Such data could be gained from Remote Sensing (RS) platforms because of their multispectral and temporal characteristics to distinguish the yield stage (Taherei Ghazvinei et al., 2018; Vieira et al., 2012). The key RS platforms used in PA to gather information about the crop features to monitor crop yield and health are Unmanned Aerial Vehicles (UAVs) and satellites. Several researchers have applied satellite imagery for sugarcane classification (Mutanga et al., 2013), monitoring land use (Abdel-Rahman and Ahmed, 2008a), varietal identification (Abdel-Rahman and Ahmed, 2008b), and Nitrogen (N) status monitoring (Bégué et al., 2010; Lamb, 2000; Simões et al., 2009). In the sugarcane yield management, satellite data such as Moderate Resolution Imaging Spectroradiometer

* Corresponding author 
(MODIS) (Xavier et al., 2006), Advanced Spaceborne Thermal Emission and Reflection Radiometer (ASTER) (Almeida et al., 2006), Landsat (Rudorff et al., 2010) and others have been utilized to detect and map the crop change (Hui Lin et al., 2009; Zhou et al., 2015). However, there are still notable limitations in the applications of satellite data in terms of resolution, extent, cost, revisit time and weather constraints (Atzberger et al., 2015). The UAV platform with distinctive characteristics, namely lower operation expense, high spatial resolution $(<1 \mathrm{~m})$, high temporal frequency and real-time capacity, gives the real-time information to farmers (Ampatzidis and Partel, 2019; Maresma et al., 2016). Consequently, monitoring crop yield status, estimating nutrient status, quantify crop water demand, estimation of plant growth, and many other practices of PA are feasible by utilizing UAVs.

Sugarcane, a perennial crop, is suitable to grow in tropical and subtropical areas such as India, Australia, and Brazil (Abdel-Rahman and Ahmed, 2008a; Rudorff et al., 2010). Optimization and accurate estimation of sugarcane crop production could be evaluated by monitoring variability of crop growth and health status during the growing season. The significance of obtaining trustworthy and frequently updated data from sugarcane lands should be considered in PA strategies to sustain the future of the industry. The most crucial component of crops in order to analyse crop growth stage and to predict crop yield is Leaf Area Index (LAI) (Haboudane, 2004), which is an important descriptor of many biological and physical processes of vegetation, including photosynthesis, respiration, nutrient cycling, transpiration and rainfall interception (Tian et al., 2017). A strong correlation has been found between canopy vegetation indices (VIs) and LAI, hence VIs are often used to estimate LAI in remote sensing methods (Tian et al., 2017).

The Normalized Difference Vegetation Index (NDVI) is one of the most commonly used VIs to estimate LAI, Nitrogen concentration, and biomass (Poorter et al., 1990), as it could reduce the atmospheric attenuation and shading impacts (Technol, 2007). Green Normalized Difference Vegetation Index (GNDVI) has been used by several authors to predict sugarcane yield and determine the temporal differences (Rahman and J. Robson, 2016). The Global Vegetation Index (GVI), likewise NDVI, is based on the contrast between the spectral responses of the visible and Near-Infrared (NIR) regions, but has the advantage of considering red, NIR, blue, and green bands to incorporate the influence of photosynthetic pigments and water content present in leaves (Benvenuti and Weill, 2010).

For the lower amount of chlorophyll, the reflectance from spectral region between the red and NIR bands, termed as the 'red edge' band, increases whereas the reflectance from NIR decreases (Diacono et al., 2013). Therefore, the extracted information from the red edge band combined with VIs could play a significant role for computing LAI. Hence, by substituting the red band with the red edge band, the Normalized Difference RedEdge (NDRE) index as a variant of the NDVI can be obtained as a reliable measure for chlorophyll and LAI status (Tilling et al., 2007).

The usage of any VIs requires careful attention to their strengths and defects and the demanding applications. The critical issues which could not be completely solved are the selection of the most appropriate data regarding temporal, spatial, and spectral resolution, and the selection of the most proper VIs to study the connection between VIs and LAI for crop status monitoring. To the best of our knowledge, no previous study has mapped LAI in a sugarcane field with both NDRE and NDVI in order to compare these VIs. In addition, the drawbacks and advantages for characterizing the sugarcane LAI from UAV images and from very high spatial resolution satellite images remain a knowledge gap in the existing literature.

This study was conducted for a sugarcane field in Bundaberg, Queensland, Australia. The overall aim of this paper is to map sugarcane crop LAI with UAV images and conduct a comparison with WorldView-2 (WV2) data. The two major specific objectives are: to analyse NDVI and NDRE for UAV and WV2 for sugarcane in the study area and compare the overall performance of UAV and WV2.

\section{DATASETS AND METHODS}

\subsection{Study Area}

The sugarcane fields in Australia can be found along a 2,000-km strip of land on the east coast from northern New South Wales to the northern Queensland. About onethird of this crop is grown in the northern Queensland. The 
study area is in the Bundaberg region, Queensland (24 ${ }^{\circ} 50^{\prime}$ $\mathrm{S}, 152^{\circ} 24^{\prime} \mathrm{E}$ ), and has an area of 3 hectares (Figure 1).

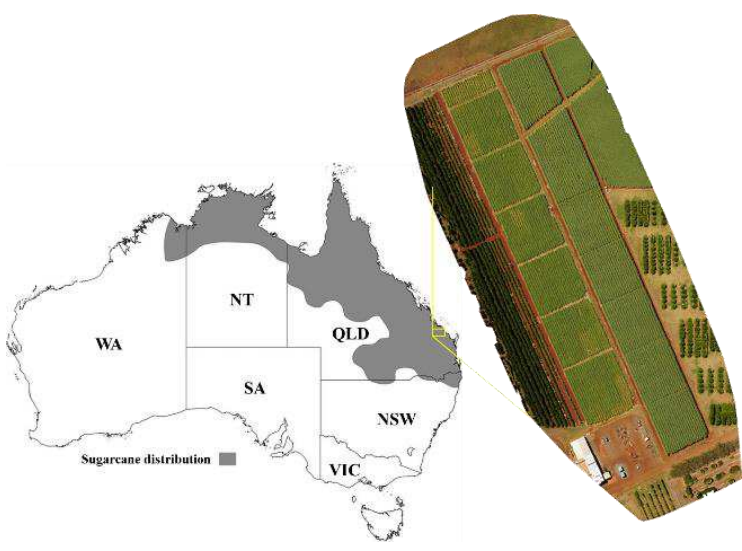

Figure 1. Sugarcane distribution map (left) and the study area (right)

\subsection{Data}

A collection of multispectral images acquired from a UAV integrated MicaSense RedEdge sensor were orthorectified and mosaicked through Pix4Dmapper software package. The UAV ortho multispectral image with a 3-cm spatial resolution was acquired on March 31, 2019. The sensor includes five bands: blue ( $460-510 \mathrm{~nm})$, green $(545-575$ $\mathrm{nm})$, red $(630-690 \mathrm{~nm})$, red edge $(712-722 \mathrm{~nm})$ and NIR (820-860 nm).

The WV2 product used in this study is a multispectral image with a 2-m spatial resolution, which was acquired on March 20, 2019, at an off-nadir view angle of $18.9^{\circ}$ and $0 \%$ cloud cover. The multispectral image includes eight bands: coastal blue $(400-450 \mathrm{~nm})$, blue $(450-510 \mathrm{~nm})$, green $(510-580 \mathrm{~nm})$, yellow $(585-625 \mathrm{~nm})$, red (630-690 $\mathrm{nm})$, red edge (705-745 nm), NIR1 (770-895 nm), and NIR2 (860-1040 nm).

\section{METHODOLOGY}

The NDVI and NDRE indices as the main parameters for characterizing the crop LAI, were derived from the two datasets, respectively from UAV and WV2, for the sugarcane fields corresponding to the approximately maximum LAI (March) over the year 2019. According to (Hui Lin et al., 2009), the life cycle of this annual irrigated crop includes five important growth stages. The period of sugarcane crop growth depending on the district varies from 10 to 18 months. The crop with the maximum LAI in the month of March in Australia, is harvested between
June and November, and regrows for harvesting approximately 12 months later (Everingham et al., 2009). The NDVI is a combination of two spectral bands, which was computed by Equation (1) in order to measure the presence of chlorophyll. A high NDVI value occurs at the peak of chlorophyll content that crops intensively absorbs red light and reflects NIR light (Bédard et al., 2006).

$$
N D V I=(N I R-R e d) /(N I R+R e d)
$$

NDRE can be formulated by the Red edge and NIR bands based on Equation (2). It is sensitive to chlorophyll content and variability in leaves. High values of NDRE show higher levels of chlorophyll content.

$N D R E=(N I R-$ Red edge $) /(N I R+$ Red edge $)$

An overall analysis of the UAV and WV2 data in terms of pixel level NDRE and NDVI was conducted to understand the difference in the spectral and spectrum variation on NDRE and NDVI, and to conduct comparison of the spatial resolution effect of different RS data on the crop yield estimation. Because of the much higher spectral and spatial resolution of the UAV images, the amount of information and spectral variation of UAV-based NDRE and NDVI are much larger than those of WV2. For the comparison between UAV and WV2, the NDRE and NDVI images of UAV were down resampled to the spatial resolution of the WV2 data based on the cubic convolution method.

To further quantify the difference between NDVI and NDRE, a total of four indicators based on statistics methods were considered i.e. maximum, minimum, mean, and standard deviation (S.D.). To analyse the absolute chlorophyll content, these statistical parameters were calculated only at sugarcane fields without considering any other features. In addition, a correlation analysis was carried out for the UAV and WV2 datasets, to observe the effect of spatial resolution changes in NDVI and NDRE maps. The correlation coefficient $\left(\mathrm{R}^{2}\right)$ is one of the most significant descriptors to describe the trend model between two different variables (Albarakat, 2019). 


\section{RESULTS}

\subsection{COMPARISON OF NDVI AND NDRE}

We performed a comparative analysis on NDVI and NDRE, both obtained from the UAV and WV2 data. The NDVI and NDRE at their original spatial resolution of the UAV and WV2 data are shown in Figures 2 and 3. To understand the relationship of the spatial patterns between the NDVI and NDRE values derived from the two sensors, the UAV data have been resampled to the same spatial resolution as the WV2 data (Figure 4). Table 1 contains statistical parameters that show the maximum value, minimum value, mean value, and S.D. value of the NDVI and NDRE between UAV and WV2 data. The first three parameters were used to describe the difference response between NDVI and NDRE to the different chlorophyll content. The minimum and maximum response ranges for the UAV data are in the similar range for both VIs, but the mean value is higher for NDVI. Therefore, it can be concluded that NDRE is more spread out than NDVI in the UAV data. Also, regarding the WV2 data, NDVI shows more discrete response range rather than NDRE. This conclusion could be also seen in difference maps obtained by subtracting NDVI_UAV from NDRE_UAV and NDVI_WV2 from NDRE_WV2 (Figure 5) where NDVI_UAV and NDRE_UAV represent the respective vegetation indices obtained from the UAV data, and NDVI_WV2 and NDRE_WV2 from the WV2 data. S.D. parameter indicates how much spectral detail is present in an area (Tian et al., 2017). A large S.D. value means that the pixel value frequency distribution is more dispersed. The results indicate that NDRE can be a more effective in the UAV data. And for the WV2 data, NDVI works better.

\begin{tabular}{|c|c|c|c|c|c|c|c|c|}
\hline & \multicolumn{2}{|c|}{ Max } & \multicolumn{2}{|c|}{ Min } & \multicolumn{2}{|c|}{ Mean } & \multicolumn{2}{|c|}{ S.D. } \\
\hline & UAV & WV2 & UAV & WV2 & UAV & WV2 & UAV & WV2 \\
\hline 穵 & 0.98 & 0.91 & 0.10 & 0.10 & 0.85 & 0.80 & 0.08 & 0.06 \\
\hline 褰 & 0.88 & 0.45 & 0.01 & 0.05 & 0.54 & 0.29 & 0.08 & 0.05 \\
\hline
\end{tabular}

Table 1. Statistics for the NDVI and NDRE of two different datasets

The comparison results of $\mathrm{R}^{2}$ for the two representative NDVI_UAV with NDRE_UAV and NDVI_WV2 with
NDRE_WV2 to measure the sugarcane LAI content indicated that the NDRE is the optimal VI for mapping the LAI with a UAV image, whereas the NDVI is more suitable for WV2 (Table 2), but both achieved a satisfactory accuracy. It could be concluded that the spectrum range of bands and spatial resolution are significant factors to select the proper VIs.

\begin{tabular}{|c|c|c|c|c|}
\cline { 2 - 5 } \multicolumn{1}{c|}{} & $\begin{array}{c}\text { NDVI } \\
\text { UAV }\end{array}$ & $\begin{array}{c}\text { NDRE } \\
\text { UAV }\end{array}$ & $\begin{array}{c}\text { NDVI } \\
\text { WV2 }\end{array}$ & $\begin{array}{c}\text { NDRE } \\
\text { WV2 }\end{array}$ \\
\hline $\begin{array}{c}\text { NDVI } \\
\text { UAV }\end{array}$ & 1 & 0.90 & 0.68 & 0.53 \\
\hline $\begin{array}{c}\text { NDRE } \\
\text { UAV }\end{array}$ & 1 & 0.59 & 0.71 \\
\hline $\begin{array}{c}\text { NDVI } \\
\text { WV2 }\end{array}$ & & 1 & 0.81 \\
\hline $\begin{array}{c}\text { NDRE } \\
\text { WV2 }\end{array}$ & & & & 1 \\
\hline
\end{tabular}

Table 2. Statistical correlation analysis between the satellite and UAV images

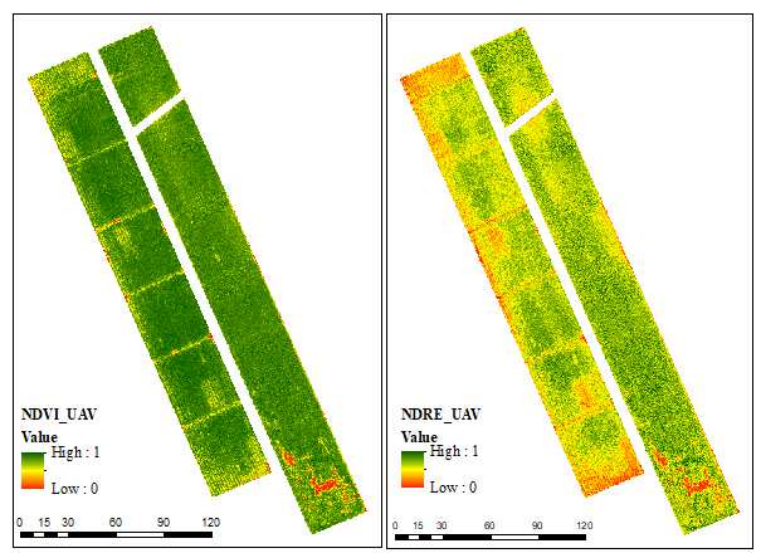

Figure 2. NDVI (left) and NDRE (right) from UAV data

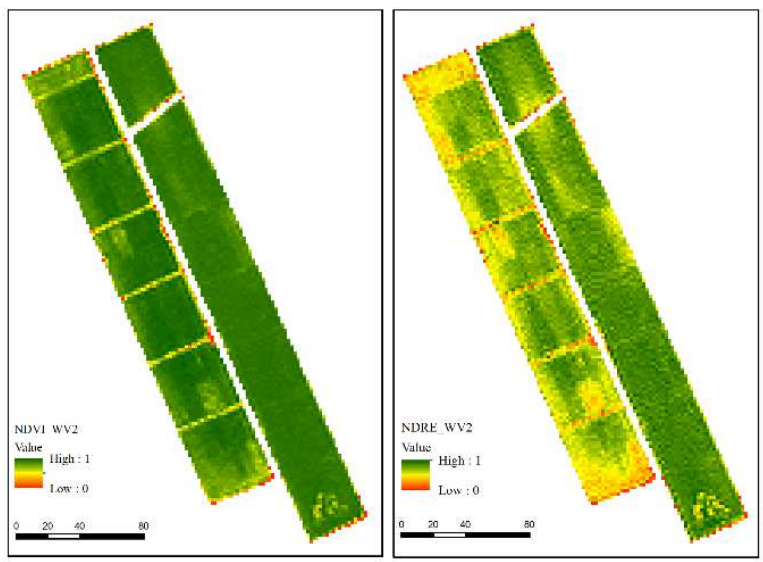

Figure 3. NDVI (left) and NDRE (right) from WV2 data 


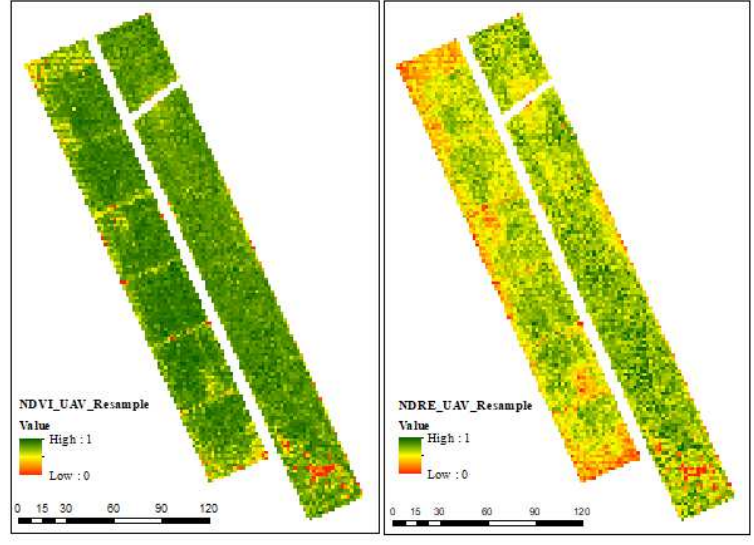

Figure 4. UAV-derived NDVI (left) and NDRE (right) resampled to the spatial resolution of WV2

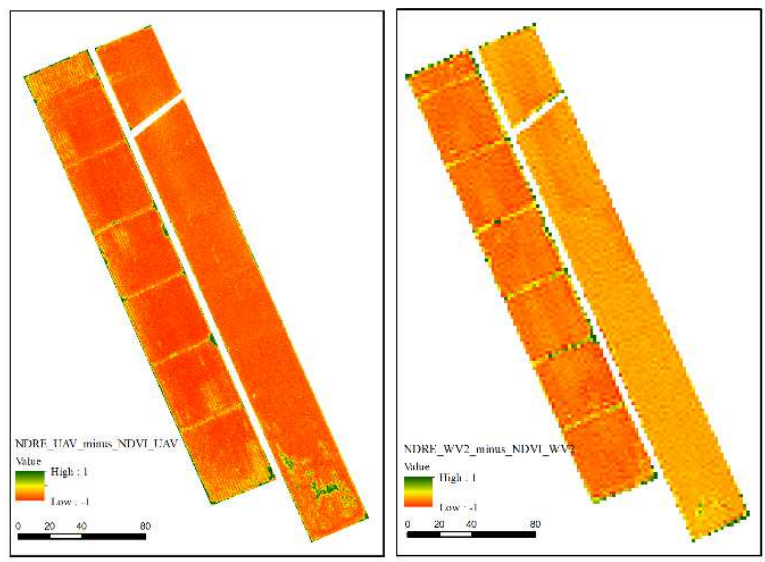

Figure 5. The difference maps between UAV vegetation indices (left) and WV2 vegetation indices (right).

\subsection{COMPARISON OF UAV AND WV2}

UAV NDVI and NDRE values are larger than WV2 NDVI and NDRE values when mapping the sugarcane crop LAI. As for the WV2 data, the mean NDVI value and the mean NDRE value are 0.05 and 0.25 less than of the UAV results, indicating that the sensitivity of WV2 to the LAI is lower than that of UAV.

Table 1 shows that the S.D. of UAV NDVI and NDRE are higher than that of WV2 NDVI and NDRE, 0.02 and 0.03 respectively, which indicates that the amount of details and spectral variation of UAV data are more abundant. In other words, UAV provides more information than WV2. This is mainly because of the spatial resolution of UAV that is much higher than that of WV2. A comparison of the $\mathrm{R}^{2}$ results between NDVI_UAV with NDVI_WV2, and NDRE_UAV with NDRE_WV2, in Table 2, indicates that the chlorophyll contents are more clear from the UAV data, which is consistent with the results of S.D. reported in Table 1.
In addition, difference maps of NDVI_UAV with NDVI_WV2 and NDVI_UAV and NDRE_WV2 indicate that the UAV data is more sensitive to chlorophyll contents in sugarcane crop (Figure 6) than the WV2 data. In conclusion, the large variation of the chlorophyll contents as indicated by the VIs derived from UAV indicates that the high spatial resolution provides great potential to characterize the high accuracy sugarcane LAI.

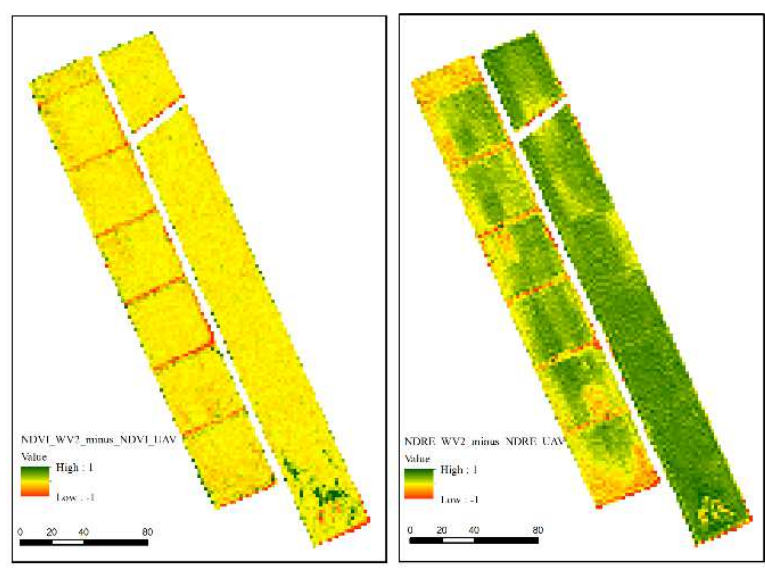

Figure 6 . The difference maps between NDVIs (left) and NDREs (right)

\section{CONCLUSION}

In this study, two VIs (NDVI and NDRE), which are often used for the estimation of LAI, were characterised using UAV and WV2 data in sugarcane fields. The results obtained from a statistical analysis showed that the NDRE had the optimal accuracy for UAV, whereas the NDVI achieved a higher accuracy for WV2. A comparison of WV2-derived LAI and UAV-derived LAI was conducted, which suggested that using high spatial resolution RS data can lead to meaningful outputs for PA in the estimation of sugarcane chlorophyll contents. Future work is to use and validate the results in other crops with other VIs.

\section{ACKNOWLEDGEMENT}

Remote sensing data were obtained from sugarcane field trials at Bundaberg Research Facility of Queensland Department of Agriculture and Fisheries. The field trial was part of the "Smart blending of enhanced efficiency fertilisers to maximise sugarcane profitability" project under the More Profit from Nitrogen Program, supported by funding from the Australian Government Department of Agriculture as part of its Rural R\&D for Profit program, Sugar Research Australia Ltd and Queensland 
Government. We thank Dr. Weijin Wang and Mr. Stephen Ginns for facilitating UAV data collection.

\section{REFERENCES}

Abdel-Rahman, E.M., Ahmed, F.B., 2008a. The application of remote sensing techniques to sugarcane (Saccharum spp. hybrid) production: a review of the literature. Int. J. Remote Sens. 29, 3753-3767. https://doi.org/10.1080/01431160701874603

Abdel-Rahman, E.M., Ahmed, F.B., 2008b. The application of remote sensing techniques to sugarcane (Saccharum spp. hybrid) production: a review of the literature. Int. J. Remote Sens. 29, 3753-3767. https://doi.org/10.1080/01431160701874603

Albarakat, R., 2019. Comparison of Normalized Difference Vegetation Index Derived from Landsat, MODIS, and AVHRR for the Mesopotamian Marshes Between 2002 and 20181245

Almeida, T.I.R., De Souza Filho, C.R., Rossetto, R., 2006. ASTER and Landsat ETM+ images applied to sugarcane yield forecast. Int. J. Remote Sens. 27, 40574069. https://doi.org/10.1080/01431160600857451

Ampatzidis, Y., Partel, V., 2019. UAV-Based High Throughput Phenotyping in Citrus Utilizing Multispectral Imaging and Artificial Intelligence. Remote Sens. 11, 410. https://doi.org/10.3390/rs11040410

Atzberger, C., Darvishzadeh, R., Immitzer, M., Schlerf, M., Skidmore, A., le Maire, G., 2015. Comparative analysis of different retrieval methods for mapping grassland leaf area index using airborne imaging spectroscopy. Int. J. Appl. Earth Obs. Geoinf. 43, 1931. https://doi.org/10.1016/j.jag.2015.01.009

Bédard, F., Crump, S., Gaudreau, J., 2006. A comparison between Terra MODIS and NOAA AVHRR NDVI satellite image composites for the monitoring of natural grassland conditions in Alberta, Canada. Can. J. Remote Sens. 32, 44-50. https://doi.org/10.5589/m06-001

Bégué, A., Lebourgeois, V., Bappel, E., Todoroff, P., Pellegrino, A., Baillarin, F., Siegmund, B., 2010. Spatio-temporal variability of sugarcane fields and recommendations for yield forecast using NDVI. Int. $J$. Remote Sens. 31, 5391-5407. https://doi.org/10.1080/01431160903349057

Benvenuti, F., Weill, M., 2010. Relationship between multi-spectral data and sugarcane crop yield. Processing 33-36

Diacono, M., Rubino, P., Montemurro, F., 2013. Precision nitrogen management of wheat. A review. Agron. Sustain. Dev. 33, 219-241. https://doi.org/10.1007/s13593-012-0111-z

Everingham, Y.L., Smyth, C.W., Inman-Bamber, N.G., 2009. Ensemble data mining approaches to forecast regional sugarcane crop production. Agric. For. Meteorol. 149, 689-696. https://doi.org/10.1016/j.agrformet.2008.10.018

Haboudane, D., 2004. Hyperspectral vegetation indices and novel algorithms for predicting green LAI of crop canopies: Modeling and validation in the context of precision agriculture. Remote Sens. Environ. 90, 337352. https://doi.org/10.1016/j.rse.2003.12.013

Huang, J., Wang, X., Li, X., Tian, H., Pan, Z., 2013. Remotely Sensed Rice Yield Prediction Using MultiTemporal NDVI Data Derived from NOAA's-AVHRR. PLoS One 8, e70816. https://doi.org/10.1371/journal.pone.0070816

Hui Lin, Jinsong Chen, Zhiyuan Pei, Songling Zhang, Xianzhi Hu, 2009. Monitoring Sugarcane Growth Using ENVISAT ASAR Data. IEEE Trans. Geosci. Remote Sens. 47, 2572-2580. https://doi.org/10.1109/TGRS.2009.2015769

Lamb, D.W., 2000. The use of qualitative airborne multispectral imaging for managing agricultural crops - a case study in south-eastern Australia. Aust. J. Exp. Agric. 40, 725. https://doi.org/10.1071/EA99086

Lamb, D.W., Steyn-Ross, M., Schaare, P., Hanna, M.M., Silvester, W., Steyn-Ross, A., 2002. Estimating leaf nitrogen concentration in ryegrass ( Lolium spp.) pasture using the chlorophyll red-edge: Theoretical modelling and experimental observations. Int. J. Remote Sens. 23, 3619-3648. https://doi.org/10.1080/01431160110114529

Lambert, D., Lowenberg-DeBoer, J., 2000. Precision Agriculture Profitability Review 154.

Maresma, Á., Ariza, M., Martínez, E., Lloveras, J., Martínez-Casasnovas, J., 2016. Analysis of Vegetation Indices to Determine Nitrogen Application and Yield Prediction in Maize (Zea mays L.) from a Standard UAV Service. Remote Sens. 8, 973. https://doi.org/10.3390/rs8120973

Mutanga, S., Schoor, C. van, Olorunju, P.L., Gonah, T., Ramoelo, A., 2013. Determining the Best Optimum Time for Predicting Sugarcane Yield Using HyperTemporal Satellite Imagery. Adv. Remote Sens. 02, 269-275. https://doi.org/10.4236/ars.2013.23029

Poorter, H., Remkes, C., Lambers, H., 1990. Carbon and nitrogen economy of 24 wild species differing in relative growth rate. Plant Physiol. 94, 621-7. https://doi.org/10.1104/pp.94.2.621

Rahman, M.M., J. Robson, A., 2016. A Novel Approach for Sugarcane Yield Prediction Using Landsat Time Series Imagery: A Case Study on Bundaberg Region. Adv. Remote Sens. 05, 93-102. https://doi.org/10.4236/ars.2016.52008

Rudorff, B.F.T., Aguiar, D.A., Silva, W.F., Sugawara, L.M., Adami, M., Moreira, M.A., 2010. Studies on the Rapid Expansion of Sugarcane for Ethanol Production in São Paulo State (Brazil) Using Landsat Data. Remote Sens. 2, 1057-1076. https://doi.org/10.3390/rs2041057 
Simões, M. dos S., Rocha, J.V., Lamparelli, R.A.C., 2009. Orbital spectral variables, growth analysis and sugarcane yield. Sci. Agric. 66, 451-461. https://doi.org/10.1590/S0103-90162009000400004

Taherei Ghazvinei, P., Darvishi, H.H., Mosavi, A., Bin Wan Yusof, K., Alizamir, M., Shamshirband, S., Chau, K.W., 2018. Sugarcane growth prediction based on meteorological parameters using extreme learning machine and artificial neural network. Eng. Appl. Comput. Fluid Mech. 12, 738-749. https://doi.org/10.1080/19942060.2018.1526119

Technol, S.C., 2007. Evaluating the Applicability of Modis Data for 26, 173-176.

Tian, J., Wang, L., Li, X., Gong, H., Shi, C., Zhong, R., Liu, X., 2017. Comparison of UAV and WorldView-2 imagery for mapping leaf area index of mangrove forest. Int. J. Appl. Earth Obs. Geoinf. 61, 22-31. https://doi.org/10.1016/j.jag.2017.05.002

Tilling, A.K., O'Leary, G.J., Ferwerda, J.G., Jones, S.D., Fitzgerald, G.J., Rodriguez, D., Belford, R., 2007.
Remote sensing of nitrogen and water stress in wheat. F. Crop. Res. 104, 77-85. https://doi.org/10.1016/j.fcr.2007.03.023

Vieira, M.A., Formaggio, A.R., Rennó, C.D., Atzberger, C., Aguiar, D.A., Mello, M.P., 2012. Object Based Image Analysis and Data Mining applied to a remotely sensed Landsat time-series to map sugarcane over large areas. Remote Sens. Environ. 123, 553-562. https://doi.org/10.1016/j.rse.2012.04.011

Xavier, A.C., Rudorff, B.F.T., Shimabukuro, Y.E., Berka, L.M.S., Moreira, M.A., 2006. Multi-temporal analysis of MODIS data to classify sugarcane crop. Int. J. Remote Sens. 27, 755-768. https://doi.org/10.1080/01431160500296735

Zhou, Z., Huang, J., Wang, J., Zhang, K., Kuang, Z., Zhong, S., Song, X., 2015. Object-Oriented Classification of Sugarcane Using Time-Series MiddleResolution Remote Sensing Data Based on AdaBoost. PLoS One 10, e0142069. https://doi.org/10.1371/journal.pone.0142069 